\title{
HELLP Syndrome or Acute Fatty Liver of Pregnancy: A Differential Diagnostic Challenge
}

\author{
Common Features and Differences
}

\section{HELLP-Syndrom oder akute Schwangerschaftsfettleber: eine differenzialdiagnostische Herausforderung}

\author{
Gemeinsamkeiten und Unterschiede
}

\section{(c) (i) (ㅇ) $\ominus$}

Authors

Werner Rath ${ }^{1}$, Panagiotis Tsikouras ${ }^{2}$, Patrick Stelz| ${ }^{3}$

Affiliations

1 Medizinische Fakultät, Gynäkologie und Geburtshilfe, Universitätsklinikum Schleswig-Holstein, Campus Kiel, Kiel, Germany

2 Democritus University of Thrace, Department of Obstetrics and Gynecology, Alexandroupolis, Greece

3 Frauenklinik, Universitätsklinikum Erlangen, Erlangen, Germany

Key words

HELLP syndrome, acute fatty liver of pregnancy, Swansea criteria, differential diagnosis, treatment and prognosis

\section{Schlüsselwörter}

HELLP-Syndrom, akute Schwangerschaftsfettleber, SwanseaKriterien, Differenzialdiagnose, Therapie und Prognose
received 6.11.2019
revised $\quad 15.12 .2019$
accepted 8.1.2020

\section{Bibliography}

DOI https://doi.org/10.1055/a-1091-8630

Geburtsh Frauenheilk 2020; 80: 499-507 @ Georg Thieme

Verlag KG Stuttgart · New York | ISSN 0016-5751

\section{Correspondence}

Univ.-Prof. Dr. med. Dr. h.c. Werner Rath

Medizinische Fakultät Gynäkologie und Geburtshilfe,

Universitätsklinikum Schleswig-Holstein, Campus Kiel

Arnold-Heller Straße 3, 24105 Kiel, Germany

Werner.Rath@uksh.de

Deutsche Version unter:

https://doi.org/10.1055/a-1091-8630

\begin{abstract}
HELLP syndrome and the less common acute fatty liver of pregnancy (AFL) are unpredictable, life-threatening complications of pregnancy. The similarities in their clinical and laboratory presentations are often challenging for the obstetrician when making a differential diagnosis. Both diseases are characterised by microvesicular steatosis of varying degrees of severity. A specific risk profile does not exist for either of the entities. Genetic defects in mitochondrial fatty acid oxidation and multiple pregnancy are considered to be common predisposing factors. The diagnosis of AFL is based on a combination of clinical symptoms and laboratory findings. The Swansea criteria have been proposed as a diagnostic tool for orientation. HELLP syndrome is a laboratory diagnosis based on the triad of haemolysis, elevated aminotransferase levels and a platelet count $<100 \mathrm{G} / \mathrm{l}$. Generalised malaise, nausea, vomiting and abdominal pain are common symptoms of both diseases, making early diagnosis difficult. Clinical differences include a lack of polydipsia/polyuria in HELLP syndrome, while jaundice is more common and more pronounced in AFL, there is a lower incidence of hypertension and proteinuria, and patients with AFL may develop encephalopathy with rapid progression to acute liver failure. In contrast, neurological symptoms such as severe headache and visual disturbances are more prominent in patients with HELLP syndrome. In terms of laboratory findings, AFL can be differentiated from HELLP syndrome by the presence of leucocytosis, hypoglycaemia, more pronounced hyperbilirubinemia, an initial lack of haemolysis and thrombocytopenia < $100 \mathrm{G} / \mathrm{l}$, as well as lower antithrombin levels $<65 \%$ and prolonged prothrombin times. While HELLP syndrome has a fluctuating clinical course with rapid exacerbation within hours or transient remissions, AFL rapidly progresses to acute liver failure if the infant is not delivered immediately. The only causal treatment for both diseases is immediate delivery. Expectant management between $24+0$ and $33+6$ weeks of gestation is recommended for HELLP syndrome, but only in cases where the mother can be stabilised
\end{abstract}


and there is no evidence of foetal compromise. The maternal mortality rate for HELLP syndrome in developed countries is approximately $1 \%$, while the rate for AFL is $1.8-18 \%$. Perinatal mortality rates are $7-20 \%$ and $15-20 \%$, respectively. While data on the long-term impact of AFL on the health of mother and child is still insufficient, HELLP syndrome is associated with an increased risk of developing cardiovascular, metabolic and neurological diseases in later life.

\section{ZUSAMMENFASSUNG}

HELLP-Syndrom und die seltenere akute Schwangerschaftsfettleber (AFL) sind unvorhersehbare, lebensbedrohliche Komplikationen in der Schwangerschaft. Klinische und laborchemische Gemeinsamkeiten stellen den Geburtshelfer häufig vor eine differenzialdiagnostische Herausforderung. Bei beiden Erkrankungen besteht eine mikrovesikuläre Steatose unterschiedlicher Ausprägung. Ein spezifisches Risikoprofil ist für beide Entitäten bisher nicht bekannt. Als gemeinsame prädisponierende Faktoren gelten genetische Defekte in der mitochondrialen Fettsäureoxidation sowie Mehrlingsschwangerschaften. Die Diagnose AFL wird aus der Kombination klinischer Symptome und laborchemischer Befunde gestellt, die Swansea-Kriterien stellen dabei eine diagnostische Orientierung dar. Das HELLP-Syndrom ist eine laborchemische Diagnose aus der Trias Hämolyse, erhöhte Transaminasen und Thrombozytopenie < $100 \mathrm{G} /$ l. Allgemeines Krankheitsgefühl, Übelkeit, Erbrechen und Abdominalschmerzen sind gemeinsame Symptome beider Erkrankungen, die eine frühe Diagno- sestellung erschweren. Klinische Unterschiede bestehen in der beim HELLP-Syndrom fehlenden Polydipsie/Polyurie und dem bei AFL häufigeren und ausgeprägteren Ikterus, dem selteneren Auftreten von Hypertonie und Proteinurie sowie in der Entwicklung einer Enzephalopathie bei zunehmendem Leberversagen. Beim HELLP-Syndrom stehen neurologische Symptome wie starke Kopfschmerzen und Visusstörungen im Vordergrund. Laborchemisch ist die AFL durch die Leukozytose, die Hypoglykämie, die ausgeprägtere Hyperbilirubinämie, die initial fehlende Hämolyse und Thrombozytopenie < $100 \mathrm{G} /$, die Verminderung der Antithrombin-Spiegel $<65 \%$ und die Verlängerung der Prothrombinzeit vom HELLP-Syndrom abzugrenzen. Während das HELLP-Syndrom in Schüben mit passageren Remissionen verlaufen kann, geht die AFL, sofern keine rasche Entbindung erfolgt, in ein akutes Leberversagen über. Die einzige kausale Therapie beider Erkrankungen ist die unverzügliche Entbindung. Beim HELLP-Syndrom wird zwischen der 24+0-33+6 SSW ein exspektatives Vorgehen empfohlen, sofern die Mutter stabilisierbar ist und keine fetale Gefährdung besteht. Die mütterliche Letalität beträgt beim HELLP-Syndrom in den Industrieländern ca. $1 \%$, bei der AFL 1,8-18\%, die perinatale Mortalität 7-20\% bzw. 15-20\%. Während bei der AFL die Langzeitauswirkungen auf Mutter und Kind bisher nicht geklärt sind, muss beim HELLP-Syndrom mit einem erhöhten Risiko für kardiovaskuläre, metabolische und neurologische Erkrankungen im späteren Leben gerechnet werden.

\section{Introduction}

Pregnancy-specific liver disorders include intrahepatic cholestasis of pregnancy (ICP), HELLP syndrome and acute fatty liver of pregnancy (AFL). ICP is the most common, with a geographically-dependent prevalence of between 0.3 and 5.6\% [1], followed by HELLP syndrome with a prevalence of $0.5-0.9 \%$ [2] and AFL with a prevalence of $0.005-0.01 \%$ [3].

ICP is defined as a reversible form of reduced bile secretion with cholestasis. HELLP syndrome is considered a severe manifestation of pre-eclampsia (not a disease in its own right) and presents with a typical triad of laboratory findings consisting of haemolysis, pathologically elevated aminotransferases and a platelet count of < $100 \mathrm{G} / \mathrm{l}$ [4]. As hypertension and proteinuria are not present in up to $15 \%$ of cases with HELLP syndrome [5], the AWMF guideline 015/018 published in 2019 [6] defines HELLP syndrome as a constellation of laboratory findings typically occurring in pregnancy, often associated with pre-eclampsia. AFL is characterised by acute liver disfunction with progression to fulminant liver failure caused by pronounced, centrilobular, microvesicular steatosis [7].

As its main symptoms are excruciating pruritus (typically worst in the palms and soles) in the late 2 nd and the 3rd trimester of pregnancy and elevated bile acid levels ( $\geq 11 \mu \mathrm{mol} / \mathrm{I}$ ), it is usually easy to distinguish ICP from HELLP syndrome and AFL. However, the similarities in clinical and laboratory findings between HELLP syndrome and AFL can pose a significant challenge when making a differential diagnosis and may lead to delays in obtaining the correct diagnosis. As both diseases are acute, life-threatening complications of pregnancy, rapid diagnosis followed by immediate treatment is of decisive prognostic importance. The common features and differences in these two entities are therefore described below.

\section{Predisposing Factors}

There is no specific risk profile for either of the two diseases. It is still unknown whether pre-existing liver disease increases the risk $[5,8]$.

HELLP syndrome in a previous pregnancy is considered a predisposing factor for the occurrence of HELLP syndrome in a subsequent pregnancy [2], this does not apply to AFL (individual cases, [9]).

According to epidemiological studies [10], nulliparity is a predisposing factor for AFL; in hypertensive diseases of pregnancy, nulliparity is a predisposing factor for pre-eclampsia but not for HELLP syndrome [11].

Multiple pregnancy is significantly more common in both disorders compared to uncomplicated singleton pregnancies: prevalence of HELLP syndrome: $0.2 \%$ of singleton pregnancies, $0.9-$ $1.4 \%$ of twin pregnancies, $2.1-10.5 \%$ with triplets; percentage of all HELLP syndromes: 10.3-15.5\% (overview in [7]). The preva- 
lence of twin pregnancies in cases with AFL is 7.1-28.6\%, which is also significantly higher $[7,10,12]$.

Male foetal gender, confirmed in $70 \%$ of cases, is a predisposing factor for AFL [12].

Being underweight $(\mathrm{BMI}<20)$ is considered a predisposing factor for AFL (increasing the risk 1.4-fold, $[10,12]$ ), while obesity $(B M I \geq 30)$ tends to be a predisposing factor for pre-eclampsia/ HELLP syndrome.

In $20-40 \%$ of cases with AFL, patients have concomitant preeclampsia, and in up to $20 \%$ of cases patients have concomitant HELLP syndrome $[13,14]$.

Autosomal recessive disorders of mitochondrial fatty acid beta-oxidation affecting the mother and the child may be important in this context, particularly deficiencies in mitochondrial trifunctional protein (MTP) and its alpha subunit long-chain 3-hydroxyacyl CoA dehydrogenase (LCHAD, overview in [15]). Foetal LCHAD deficiency was confirmed in around $20 \%$ of cases with AFL [10], most commonly the mutation $1528 \mathrm{G} \rightarrow \mathrm{C}$ in exon 15 [16]. LCHAD catalyses the penultimate step in the mitochondrial beta-oxidation of long-chain fatty acids. Decreased maternal and placental fatty acid catabolism leads to an accumulation of 3-hydroxy fatty acid intermediates in the maternal circulation, leading to hepatotoxicity; $50-70 \%$ of mothers with LCHAD-deficient foetuses develop a maternal liver disorder including AFL [17]. Infants with homozygous LCHAD deficiency have a $38 \%$ mortality rate within 3 months of the diagnosis due to severe hypoglycaemia and liver failure [18]. Testing for LCHAD deficiency is part of neonatal screening in Germany.

But there is also an association with pre-eclampsia and HELLP syndrome. Heterozygous mothers of LCHAD-deficient infants have a $77 \%$ risk of developing AFL or HELLP syndrome [19].

\section{Clinical Symptoms, Complications and Course}

Both disorders predominantly present between the 28th-36th week of gestation (median time of presentation for HELLP syndrome is week 34 of gestation; [5], median time of presentation for AFL is week 36 of gestation $[10,12])$, rarely before week 22 . In 7-30\% of cases, HELLP syndrome occurs up to 48 (72) hours post partum [20]. In the largest prospective study to date, the diagnosis of AFL was made postnatally in 15 out of 57 cases [10].

HELLP syndrome is characterised by a classic triad of laboratory findings, consisting of haemolysis, elevated aminotransferase levels and thrombocytopenia < $100 \mathrm{G} / \mathrm{l}$; this is considered diagnostic proof of disease. Currently, a diagnosis of AFL is made based on clinical symptoms and laboratory findings (previously: liver biopsy). The Swansea criteria provide a diagnostic orientation [21] and are summarised in $>$ Table $\mathbf{1}$. After excluding other liver function disorders (particularly HELLP syndrome), at least 6 of the criteria must be present. In a study of 24 patients, the sensitivity of this method was reported to be $100 \%$, the specificity was $57 \%$, the positive predictive value was $85 \%$ and the negative predictive value was $100 \%$ [22]. However, the Swansea criteria are still a matter of controversial debate $[10,12,15]$. Firm evidence that taking these criteria into account will result in earlier diagnoses of AFL is still lacking [15]; around $40 \%$ of pregnant women with AFL (later
- Table 1 Swansea criteria for the diagnosis of acute fatty liver of pregnancy [21].

\begin{tabular}{|c|c|c|}
\hline $\begin{array}{l}\text { Clinical } \\
\text { symptoms }\end{array}$ & $\begin{array}{l}\text { 1. Nausea, vomiting } \\
\text { 2. Abdominal pain } \\
\text { 3. Polydipsia/polyuria } \\
\text { 4. Encephalopathy }\end{array}$ & $\begin{array}{l}\text { Diagnosis of } \\
\text { exclusion } \\
\text { (e.g. HELLP } \\
\text { syndrome): } \\
\text { At least } 6 \text { criteria } \\
\text { must be present! }\end{array}$ \\
\hline Ultrasound & 5. Ascites or "bright" liver & \\
\hline $\begin{array}{l}\text { Laboratory } \\
\text { findings }\end{array}$ & $\begin{array}{l}\text { 6. Serum creatinine } \uparrow \\
\quad(>150 \mu \mathrm{mol} / \mathrm{l}) \\
\text { 7. Leucocytosis }>11000 / \mu \mathrm{l} \\
\text { 8. Aminotransferases } \uparrow \\
\quad(>42 \mathrm{U} / \mathrm{l}) \\
\text { 9. Bilirubin } \uparrow(>14 \mu \mathrm{mol} / \mathrm{l}) \\
\text { 10. Hypoglycaemia }(<4 \mathrm{mmol} / \mathrm{l}) \\
\text { 11. Uric acid } \uparrow(>340 \mu \mathrm{mol} / \mathrm{l}) \\
\text { 12. Ammonia } \uparrow(>47 \mu \mathrm{mol} / \mathrm{l}) \\
\text { 13. Coagulopathy }(\mathrm{PT}>14 \mathrm{~s} \text { or } \\
\text { aPTT }>34 \mathrm{~s}) \\
\text { 14. Liver biopsy: microvesicular } \\
\text { steatosis }\end{array}$ & \\
\hline
\end{tabular}

confirmed by liver biopsy) in accordance with the Swansea criteria also met the criteria for HELLP syndrome [22].

The common clinical symptoms at the beginning of both disorders such as general malaise, nausea, vomiting, and abdominal pain are rather unspecific. In HELLP syndrome, upper abdominal pain/epigastric pain is considered clinically indicative, while in AFL abdominal pain is not unambiguously localised ( $\triangleright$ Table 2 ). Polydipsia/polyuria is not present in HELLP syndrome; depending on the severity of HELLP syndrome, oliguria is more likely to be a presenting symptom as a sign of renal dysfunction. Hypertension and proteinuria are less common in AFL, occurring in $20-40 \%$ of cases with AFL, compared to a prevalence of $85 \%$ in patients with HELLP syndrome (overview in [7]), although $12-18 \%$ of cases with HELLP syndrome do not have hypertension, 14\% do not have proteinuria, and neither hypertension nor proteinuria was found in up to $15 \%$ of these women $[2,5]$.

The presentation of encephalopathy caused by elevated ammonia levels in the blood ranges from initial sleep disturbances/ slight confusion to strong disorientation, flapping tremor and comatose state. In contrast, neurological symptoms such as strong headache (33-61\%) and visual disturbances (10-20\% of cases) predominate in HELLP syndrome [5, 23].

With an incidence of $27-38,6 \%[10,12]$, ascites is more common in AFL than in HELLP syndrome where the reported incidence ranges from 4-11\% [2]; subcapsular liver haematoma is more common in HELLP syndrome (0.9-1.6\%) than AFL (individual cases). Liver rupture occurs in around $1 \%$ of cases with HELLP syndrome [20], while it has only been reported in individual cases with AFL $[24,25]$.

In the study by Chen et al. [12] the rate of acute pancreatitis, which is associated with an unfavourable prognosis, was $13.6 \%$ in patients with AFL, while the rate of acute pancreatitis in severe 
- Table 2 Comparison of the prevalence of clinical symptoms and complications in acute fatty liver of pregnancy and HELLP syndrome (ranges obtained from individual studies: data from [7] and [23]).

\begin{tabular}{|l|l|l|}
\hline Criteria & Acute fatty liver of pregnancy & HELLP syndrome \\
\hline General malaise & $78 \%$ & $100 \%$ \\
\hline Nausea/vomiting & $50-82 \%$ & $29-84 \%$ \\
\hline Abdominal pain & $32-70 \%$ & $40-90 \%$ \\
\hline Polydipsia/polyuria & $11-82 \%$ & - \\
\hline Jaundice/dark urine & $29-100 \%$ & $5 \%$ \\
\hline Encephalopathy & $9-91 \%$ & neurolog. symptoms: $33-61 \%$ e.g. headache \\
\hline Hypertension/proteinuria & $20-40 \%$ & $85 \%$ \\
\hline Acute kidney failure & $14-90 \%$ & $1.2-8 \%$ \\
\hline Coagulopathy & $36-87 \%$ (DIC: $10-48 \%)$ & DIC $21 \%(2-39 \%)$ \\
\hline Lung oedema & $5-30 \%$ & $6-8 \%$ \\
\hline Gastrointestinal bleeding & $5-36 \%$ & rare \\
\hline Liver haematoma & individual cases & $0.9-1.6-(2) \%$ \\
\hline DIC: disseminated intravascular coagulation & & \\
\hline
\end{tabular}

pre-eclampsia/HELLP syndrome reported in the observational study by Sang et al. [26] was $1.2 \%$.

Gastrointestinal bleeding is more common in patients with AFL ( $\triangleright$ Table 2); it only occurs in individual cases with HELLP syndrome as an initial manifestation of the disease caused by pronounced coagulopathy [27].

The incidence of lung oedema varies depending on the respective disease ( $\triangleright$ Table 2). Coagulopathy (prolonged prothrombin time and aPTT) is present in up to $87 \%$ of cases with AFL [10]. With progressive liver failure, coagulopathy in women with AFL is a consequence of reduced synthesis of coagulation factors produced in the liver. Manifest coagulopathy with disseminated intravascular coagulation (Quick, PT, aPTT) in patients with HELLP syndrome is rare and is the result of pronounced DIC/disseminated intravascular coagulation in patients with severe disease progression. Thrombocytopenia caused by the sequestration of platelets in the peripheral circulation due to microangiopathy is always present.

\section{Laboratory Investigations and Diagnostic Procedures}

HELLP syndrome is a microangiopathic haemolytic anaemia. Haemolysis accompanied by decreased haptoglobin levels is found in $95-97 \%$ of cases, increased total bilirubin levels in $47-62 \%$ and fragmented erythrocytes in peripheral blood smear in $54-88 \%$ of patients $[2,5,23]$. Despite the presence of anaemia, haemoglobin levels may still be within normal ranges due to haemoconcentration (reduced plasma volume).

Signs of haemolysis are rare in manifestations of AFL and usually only occur in the context of multi-organ failure.

Hyperbilirubinemia is more common and more pronounced with AFL (elevated direct conjugated bilirubin levels due to intrahepatic cholestasis) than in HELLP syndrome where indirect, un- conjugated bilirubin levels are elevated due to haemolysis (overview in [28]).

Although determining the haptoglobin levels (acute-phase protein synthesised in the liver) might be useful for diagnostic differentiation of the two entities, there exist currently no studies on haptoglobin levels in AFL.

Aminotransferase levels are elevated in both disorders, although this increase is usually more pronounced in AFL than in HELLP syndrome.

Hypoglycaemia and leucocytosis are typical signs of AFL which do not occur with HELLP syndrome.

Thrombocytopenia < $100 \mathrm{G} / \mathrm{l}$ is a necessary criterion of HELLP syndrome; it is usually not detected as a manifestation of AFL but develops as a secondary symptom in the context of DIC. In nonbleeding pregnant women, a lack of thrombocytopenia combined with reduced antithrombin $<65 \%$ indicates $\mathrm{AFL}$; the reduction in antithrombin levels is significantly less pronounced in HELLP syndrome [7].

Increased serum creatinine is more common and more pronounced in AFL than in HELLP syndrome.

Prolonged clotting times (INR, PT, aPTT) occur significantly more often in AFL than in HELLP syndrome (see above). Increased ammonia levels and elevated lactic and amino acid levels in blood indicating mitochondrial damage are typical for AFL [29].

Liver ultrasound should be a standard procedure in patients with HELLP syndrome to exclude subcapsular liver haematoma/ liver rupture. In patients with AFL, changes found on ultrasound such as brightness or fatty infiltrations of the liver are unspecific and do not point at a specific diagnosis (overview in [15]).

Liver biopsy: Formerly the gold standard for the diagnosis of AFL, it is now only carried out in unclear cases where the clinical and laboratory findings do not permit diagnosis [15, 30]. As there is a significant risk of bleeding in cases with coagulopathy, biopsies in such cases should not be carried out percutaneously but should use a transjugular approach [15]. Liver biopsy is not indicated in HELLP syndrome. Microvesicular steatosis is a morpholog- 
ical sign in both AFL and HELLP syndrome [31,32], although in contrast to AFL, fibrin deposition in the liver sinusoids is found in HELLP syndrome [33].

Overall, the morphological findings of a liver biopsy are inappropriate for obtaining a differential diagnosis [7, 15].

\section{Course of Disease}

In up to $46 \%$ of cases, HELLP syndrome manifests as episodic exacerbations and transient remissions [34], but the syndrome can become acute within hours, with a risk of life-threatening complications and the development of DIC [5].

To date, there are no reports of spontaneous remission of AFL prior to delivery of the infant [35]. The characteristic course is a progressive course to acute liver failure within 1 (2) weeks, which is characterised by increasing jaundice (this only occurs in $5 \%$ of cases with HELLP syndrome), hypoglycaemia, development of coagulopathy, ascites/pleural effusions, encephalopathy and acute kidney failure in up to $90 \%$ of affected women (up to $8 \%$ of patients with HELLP syndrome) ( $\triangleright$ Table 2 ). In a recent study by Chen et al. $(n=44)$, the incidence of multi-organ failure in AFL was $38.6 \%$; the reason cited was the delay in referring these pregnant women to a perinatal centre [12]. The latency period between making the diagnosis and delivery of the infant also has an impact on prognosis of women with acute HELLP syndrome [5, 36].

After the birth, clinical and laboratory findings usually return to normal ranges within 7-10 days in both diseases [5, 15]. However, in patients with AFL there is a significant negative correlation between hyperbilirubinemia, reduced total protein, thrombocytopenia and prolonged thrombin time $[12,37]$. In patients with HELLP syndrome, no platelet increase within 98 hours is considered to indicate severe disease with a risk of multi-organ failure [38].

\section{Therapeutic Approach}

As AFL und HELLP syndrome are incalculable life-threatening complications, patients should be treated in a perinatal centre with a neonatal intensive care unit.

Terminating the pregnancy is considered the only "causal" therapy for both disorders. With AFL, there is no spontaneous remission of disease prior to termination of the pregnancy [35]. In patients with HELLP syndrome, acute exacerbation or recurrent relapses without a definitive "cure" can also make it necessary to terminate the pregnancy. Given the course of AFL and its progression to acute liver failure irrespective of gestational age, rapid delivery is required [39]. The Italian Association for the Study of the Liver (AISF) supports terminating the pregnancy at the latest within one week from the manifestation of symptoms [3]. For patients with HELLP syndrome, conservative management in a perinatal centre is possible between GW $24+0$ and GW $33+6$ if the mother is stable and the foetus is not compromised [6]. It is important to monitor mother and foetus for any criteria requiring immediate termination of the pregnancy for foetal (e.g. pathological CTG/Doppler findings) or maternal indications (such as increasing renal failure, acute lung oedema, signs of DIC, placental abruption, persistent severe abdominal pain, sudden CNS symp- toms or eclamptic seizure) [6]. After $34+0$ weeks of gestation, immediate delivery is recommended for patients with HELLP syndrome [6].

For both entities, initial treatment consists of stabilising the mother: in patients with AFL this will include supportive measures such as increasing the fluid intake and correction of metabolic acidosis, electrolyte imbalance, hypoglycaemia and coagulopathy [35]; in patients with HELLP syndrome stabilisation includes the administration of antihypertensive drugs and anticonvulsant prophylaxis/treatment with magnesium sulphate; the administration of glucocorticoids for antenatal lung maturation before $<34+0$ weeks of gestation is mandatory [6].

Plasmapheresis after the birth has been successfully carried out in individual cases with severe course of disease/life-threatening complications [40-42]. According to a meta-analysis by Wang et al. [43], delivery by Caesarean section significantly decreased maternal mortality in cases with AFL compared to vaginal delivery/induced labour, reducing maternal mortality by $44 \%$ (RR 0.56; 95\% Cl: 0.41-0.76) and also reducing perinatal mortality (RR 0.52; 95\% Cl: 0.38-0.71). Patients with acute HELLP syndrome, particularly cases with an unripe cervix remote from term, should be delivered by Caesarean section [5].

Liver transplantation may be a last resort for individual patients with AFL, particularly if their liver function continues to deteriorate, or for patients with encephalopathy and elevated lactic acid levels, concomitant sepsis or hypoxic/ischaemic liver damage [13]. For patients with HELLP syndrome, liver rupture with extensive organ damage may be an indication for liver transplantation [44].

\section{Prognosis}

While in the 1980s, maternal mortality for AFL was still around $85 \%$, advances in intensive care over the last 20 years, early diagnosis due to increased awareness of the disorders, and immediate delivery has reduced this rate since the beginning of the millennium to $10-15 \%[10,45]$. In the largest epidemiological study $(n=57)$, maternal mortality was only $1.8 \%$ [10], although the rate reported in another large study from China $(n=44)$ was $18.2 \%$. This comparatively high rate of maternal mortality was predominantly caused by delays in referring the pregnant woman to a perinatal centre [12]. Causes of death from AFL are the consequences of liver/multi-organ failure. Maternal mortality rates from HELLP syndrome are currently around $1 \%$ in developed countries but can be as high as $30 \%$ in developing countries [23]. The leading cause of maternal death from HELLP syndrome is intracerebral haemorrhage in 26-64\% of cases; DIC/multi-organ failure, hepatic bleeding or acute kidney failure are less common causes (overview in [46]).

Perinatal mortality from AFL ranges from 9-23\% $[3,15]$ and from $7-20 \%$ in patients with HELLP syndrome [23].

The average risk of recurrence in a subsequent pregnancy is $7 \%$ (4-19\%, [47]) for HELLP syndrome and $12.8 \%$ according to a Germanwide study [48]. Recurrence of AFL in subsequent pregnancies has only been reported in individual cases [10]; however, the risk of recurrence is significantly higher in cases with genetic defects of fatty acid oxidation and can be up to $25 \%[3,49]$. 


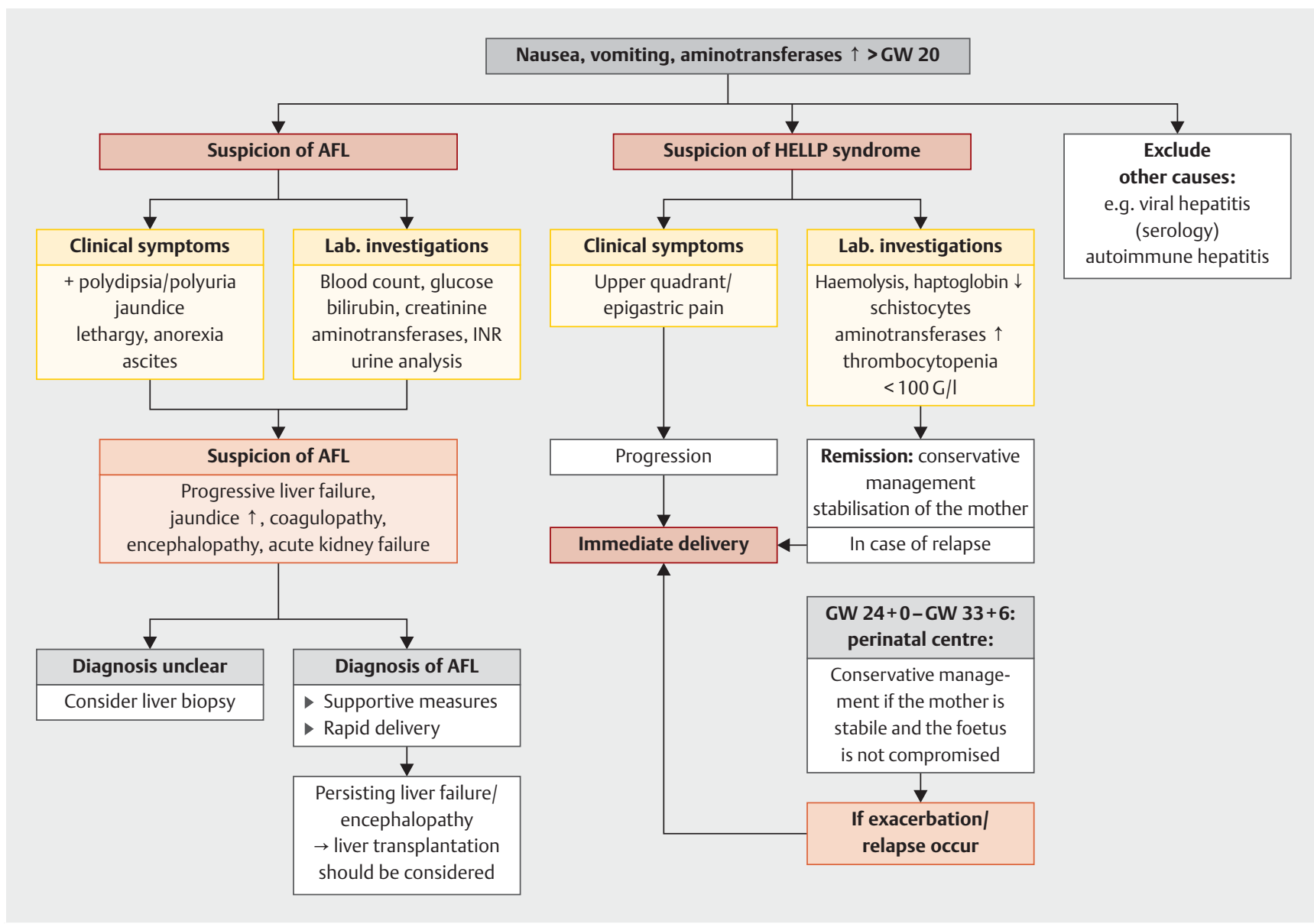

- Fig. 1 Action algorithm for women with suspected AFL/HELLP syndrome.

The risk of complications in later life for women with AFL has not been sufficiently investigated to date [15]. Follow-up studies up to an average of 54 months after the event $(n=25)$ found no significant adverse maternal outcomes [50]. In contrast, women with preeclampsia/HELLP syndrome are at increased risk of cardiovascular and metabolic diseases and neurological disorders in later life [51, 52].

\section{Discussion}

Because of the similarities in terms of clinical findings and lab test results, HELLP syndrome and acute fatty liver of pregnancy are a differential diagnostic challenge for obstetricians [7].

Based on an AFL incidence of 1:15000 pregnancies, HELLP syndrome is 72 times more common In Caucasian populations than AFL [14].

Varying degrees of microvesicular steatosis are a common morphological feature of both diseases [7].

There is no specific risk profile for both entities. With regard to HELLP syndrome, it is worth bearing in mind that the average risk of recurrence in a subsequent pregnancy is 7\% (4-19\%) [47], while the risk of recurrence of AFL is only increased if there are genetic defects of fatty acid oxidation [49].
The prevalence of multiple pregnancies is significantly higher in HELLP syndrome and AFL compared to uncomplicated singleton pregnancies; for AFL the increased risk with multiple pregnancy is ascribed to increased foetal production of fatty acid metabolites which have a hepatotoxic effect [53]; with regard to HELLP syndrome, the increased risk is due to inadequate adaptation of the maternal circulation in placental ischaemia and its complications.

Pregnant women whose foetuses have mitochondrial fatty acid oxidation defects (e.g. LCHAD deficiency) have a significantly higher risk of liver function disorders (overview in [15]). According to studies by Jebbink et al. [19], heterozygous mothers of LCHADdeficient foetuses have a $77 \%$ risk of developing AFL or HELLP syndrome.

The carrier incidence for LCHAD deficiency in the USA is $1: 675$ [54].

A detailed overview of this topic is given in the review by Liu et al. 2017 [15].

Differences between HELLP syndrome and AFL with regard to clinical and laboratory findings as well as the course of disease can be explained by the different pathogenesis of the two diseases. Generalised endothelial dysfunction with vasoconstriction/ vasospasms, disturbances of microcirculation and activation of intravascular clotting which occurs with HELLP syndrome lead to mi- 
croangiopathic haemolytic anaemia with haemolysis and pronounced thrombocytopenia as a consequence of microthrombosis of liver arterioles leading to liver cell necrosis, and elevated aminotransferase levels.

In contrast, dysfunction in AFL is initially limited to the liver and is caused by pronounced microvesicular steatosis; as the liver's metabolic capacity progressively decreases, this has a systemic effect (e.g. encephalopathy), potentially leading to multi-organ failure.

The problem is to detect either of the two diseases at an early stage as, initially, patients with HELLP syndrome or AFL present with unspecific symptoms such as general malaise, nausea, vomiting and abdominal pain.

An appropriate action algorithm outlining the procedure which should be followed in cases with suspicion of either of the disorders is shown in $>$ Fig. 1.

Whether and to what extent the Swansea criteria are useful for diagnosing AFL is still a matter of debate [15]. In their study of 24 pregnant women with AFL, Goel et al. [22] found that the Swansea criteria had high positive and negative predictive values (85 and $100 \%$, respectively). Their findings were confirmed by Knight et al. [10], who reported that the Swansea criteria had a high diagnostic reliability (90\%). After critically evaluating this study, Minakami et al. [7] concluded that the Swansea criteria are only suitable to diagnose AFL in critically ill pregnant women. Other problems associated with the Swansea criteria are their lack of standardisation [15] and their use to differentiate AFL from HELLP syndrome which should, in fact, be excluded prior to applying the criteria [21] but occurs concomitantly with AFL in up to $20 \%$ of cases $[13,14]$. In one study, 8 out of 20 patients with AFL (subsequently confirmed by liver biopsy) who met the Swansea criteria also met the criteria for HELLP syndrome [22]. A closer look at the 14 Swansea criteria shows that up to 8 of these criteria (nausea/vomiting, abdominal pain, ascites, elevated creatinine, aminotransferase, bilirubin and uric acid levels as well as microvesicular steatosis on liver biopsy) can also apply to HELLP syndrome.

Differences in clinical presentation between the two entities include the absence of polydipsia/polyuria in HELLP syndrome. Jaundice is more common and more pronounced in AFL while the incidence of hypertension/proteinuria is lower. With increasing liver failure, patients with AFL may also develop encephalopathy. In contrast, the most prominent symptoms of HELLP syndrome are neurological symptoms such as severe headache and/or visual disturbances. Potential organ complications (e.g. acute renal failure, lung oedema) are similar for both diseases, although they occur more commonly with AFL than with HELLP syndrome (cf. > Table 2).

The diagnosis of HELLP syndrome is based on laboratory findings, while the diagnosis of AFL is based on a combination of clinical symptoms and laboratory findings. The differences with regard to clinical and laboratory findings and the differentiation between these entities and other liver diseases are shown in > Table 3.

Laboratory findings are the most effective way of differentiating AFL from HELLP syndrome, with AFL characterised by leucocytosis, hypoglycaemia, a less common incidence of proteinuria, elevated direct bilirubin levels indicating intrahepatic cholestasis (HELLP syndrome: elevation of indirect bilirubin levels as a consequence of haemolysis), an initial absence of haemolysis, thrombo-

- Table 3 Differential diagnosis for HELLP syndrome - liver disorders in pregnancy (data from [23, 27, 46]).

\begin{tabular}{|c|c|c|c|c|}
\hline Criteria & HELLP syndrome & $\begin{array}{l}\text { Acute fatty liver } \\
\text { of pregnancy }\end{array}$ & Hepatitis & $\begin{array}{l}\text { Intrahepatic } \\
\text { pregnancy cholestasis }\end{array}$ \\
\hline Peak manifestation & 3rd trimester/pp. & 3rd trimester/pp. & at any time & $>60 \%$ in 3rd trimester \\
\hline Haemolysis & +++ & $+1-$ & - & - \\
\hline Aminotransferases $\uparrow$ & +++ & +++ & +++ & $+(+)$ \\
\hline Hypertension & ++ & + & - & - \\
\hline Proteinuria & $++(+)$ & + & - & - \\
\hline Leucocytosis & - & +++ & $+(+)$ & - \\
\hline Thrombocytopenia & +++ & $+\rightarrow++$ secondary & - & - \\
\hline Neurological symptoms & $+\rightarrow+++$ & ++ & - & - \\
\hline Renal insufficiency & + & ++ secondary & - & - \\
\hline Jaundice & $+1-$ & ++ & ++ & $+(+)$ \\
\hline Other & $\begin{array}{l}\text { DIC } \\
\text { liver haematoma/ } \\
\text { liver rupture }\end{array}$ & $\begin{array}{l}\text { hypoglycaemia } \\
\text { encephalopathy } \\
\text { coagulopathy } \rightarrow \text { bleeding } \\
\text { Swansea criteria }\end{array}$ & serology & $\begin{array}{l}\text { pruritus } \\
\text { bile acid in blood } \uparrow\end{array}$ \\
\hline $\begin{array}{l}\text { pp.: post partum } \\
+/-: \text { occasionally }(0-20 \% \\
+: \text { moderately often/oft } \\
++: \text { often }(>50-80 \%) \\
+++: \text { very often/constan }\end{array}$ & $\begin{array}{l}0-50 \%) \\
30-100 \%)\end{array}$ & & & \\
\hline
\end{tabular}


cytopenia < $100 \mathrm{G} / \mathrm{l}$, decreased antithrombin by < $65 \%$ and prolonged prothrombin times $[15,27,28,35]$. In addition, a pathologically elevated sFIT-1/PIGF ratio may facilitate the differentiation between HELLP syndrome and AFL. Coagulopathy with prolongation of clotting times (prothrombin time, aPTT) due to reduced liver synthesis of clotting factors is more common with AFL [7] but occurs less common with HELLP syndrome where it is caused by DIC as a consequence of severe disease progression [ 5 , 55].

While HELLP syndrome takes a fluctuating course with transient remissions or acute exacerbation of disease within a few hours, AFL will progress to acute liver failure if the pregnancy is not terminated $[5,35]$. The postoperative course is similar for both diseases, and normalisation of clinical and laboratory findings usually occurs within 1-2 weeks.

Early termination of the pregnancy is the only causal therapy for both entities $[15,27,35]$. Immediate delivery irrespective of the week of gestation is mandatory for AFL. In contrast, conservative management is recommended for HELLP syndrome [6] between $24+0$ and $33+6$ weeks of gestation, as long as the mother can be stabilised with antihypertensive and anticonvulsive medication and there are no signs of foetal compromise. The recommendations of AWMF guideline 015/018 [6] on terminating pregnancy for fetal and/or maternal indications should be followed.

The latency period between making the diagnosis and delivery has a significant impact on prognosis for AFL and acute HELLP syndrome $[5,12]$. The advances in intensive care and the more rapid time to establish diagnosis followed by immediate delivery has significantly reduced maternal mortality rates for both entities in the last $20-30$ years $[2,15]$, with the maternal mortality rate for AFL decreasing to $1.8-18 \%[10,12]$ and the mortality rate for HELLP syndrome dropping to around $1 \%$ in developed countries [23].

Perinatal mortality rates for HELLP syndrome are 7-20\% [23] and $9-23 \%$ for AFL [3].

The long-term effects of AFL on the later life of mother and child have not yet been sufficiently studied $[15,56]$. It is known that HELLP syndrome is associated with an increased risk of cardiovascular disease/stroke for mother and child in later life [52].

\section{Conclusion}

HELLP syndrome and AFL are acute life-threatening complications of pregnancy. Similarities in their clinical and laboratory findings may lead to significant problems in differential diagnosis. Obstetricians must therefore be aware of the important differences between both diseases. Early diagnosis and immediate delivery have a significant impact on prognosis for both AFL and acute HELLP syndrome.

Important topics for future studies should include further investigations on predisposing factors (e.g. genetics, concomitant diseases, environmental factors), the development of predictive models to determine the course and progression of disease and, for AFL, studies on the long-term impact of the disorder on mother and child.

\section{Conflict of Interest}

The authors declare that they have no conflict of interest.

\section{References}

[1] Bicocca MJ, Sparling JD, Chauhan SP. Intrahepatic cholestasis of pregnancy: Review of six national and regional guidelines. Eur J Obstet Gynecol Reprod Biol 2018; 231: 180-187

[2] Haram K, Svendson E, Abilgaard U. The HELLP syndrome: clinical issues and management: a review. BMC Pregnancy Childbirth 2009; 9: 8

[3] Italian Association for the Study of the Liver (AISF). AISF Position Paper on liver disease and pregnancy. Dig Liver Dis 2016; 48: 120-137

[4] Brown MA, Magee LA, Kenny LC et al. Hypertensive Disorders of Pregnancy: ISSHP Classification, diagnosis, and management recommendations for international practice. Hypertension 2018; 72: 24-43

[5] Rath W, Faridi A, Dudenhausen JW. HELLP syndrome. J Perinat Med 2000; 28: 249-260

[6] AWMF-Leitlinie 015/018, 2019. Hypertensive Schwangerschaftserkrankungen: Diagnostik und Therapie. Online: www.dggg.de; last access: 03.11.2019

[7] Minakami H, Morikawa M, Yamada T et al. Differentiation of acute fatty liver of pregnancy from syndrome of hemolysis, elevated liver enzymes and low platelet counts. J Obstet Gynaecol Res 2014; 40: 641-649

[8] Ko H, Yoshida EM. Acute fatty liver of pregnancy. Can J Gastroenterol 2006; 20: 25-30

[9] Bacq Y, Assor P, Gendrot C et al. Recurrent acute fatty liver of pregnancy. Gastroenterol Clin Biol 2007; 31: 1135-1138

[10] Knight M, Nelson-Piercy C, Kurinczuk JJ et al. A prospective national study of acute fatty liver of pregnancy in UK. Gut 2008; 57: 951-956

[11] Audibert F, Friedman SA, Frangieh AY et al. Clinical utility of strict diagnostic criteria for the HELLP syndrome. Am J Obstet Gynecol 1996; 175: 460-468

[12] Chen G, Huang K, Ji B et al. Acute fatty liver of pregnancy in a Chinese tertiary care center: a retrospective study. Arch Gynecol Obstet 2019; 300: 897-901. doi:10.1007/s00404-019-05259-w

[13] Nelson DB, Yost NP, Cunningham FG. Acute fatty liver of pregnancy: clinical outcomes and expected duration of recovery. Am J Obstet Gynecol 2013; 209: 456.e1-456.e7

[14] Allen AM, Kim WR, Larson J] et al. The epidemiology of liver diseases unique to pregnancy in a US community: a population-based study. Clin Gastroenterol Hepatol 2016; 14: 287-294

[15] Liu J, Ghaziani TT, Wolf JL. Acute fatty liver disease of pregnancy: Up dates in pathogenesis, diagnosis, and management. Am J Gastroenterol 2017; 112: 838-846

[16] Sims HF, Brackett JC, Powell CK et al. The molecular basis of pediatric long chain 3-hydroxyacyl-CoA dehydrogenase deficiency associated with maternal acute fatty liver of pregnancy. Proc Natl Acad Sci U S A 1995; 92: 841-845

[17] Browning MF, Levy HL, Wilkins-Haug LE et al. Fetal fatty acid oxidation defects and maternal liver disease in pregnancy. Obstet Gynecol 2006; 107: $115-120$

[18] den Boer ME, Wanders RJ, Morris AA et al. Long chain 3-hydroxyacyl-CoA dehydrogenase deficiency: clinical presentation and follow-up of 50 patients. Pediatrics 2002; 109: 99-104

[19] Jebbink ], Wolters A, Fernando F et al. Molecular genetics of preeclampsia and HELLP syndrome - a review. Biochim Biophys Acta 2012; 1822: 1960-1969

[20] Sibai BM, Ramadan MK, Usta I et al. Maternal morbidity and mortality in 442 pregnancies with hemolysis, elevated liver enzymes, and low platelets (HELLP syndrome). Am J Obstet Gynecol 1993; 169: 1000-1006 
[21] Ch'ng CL, Morgan M, Hainsworth I et al. Prospective study of liver dysfunction in pregnancy in Southwest Wales. Gut 2002; 51: 876-880

[22] Goel A, Ramakrishna B, Zachariah U et al. How accurate are the Swansea criteria to diagnose acute fatty liver of pregnancy in predicting hepatic microvesicular steatosis? Gut 2011; 60: 138-139

[23] Sibai BM. HELLP syndrome. 2019. Online: www.uptodate.com; last access: 03.11.2019

[24] Rahman TM, Philips M, Wendson J et al. Rare fetal complications of acute fatty liver of pregnancy. Crit Care 2000; 3 (Suppl. 1): 186

[25] Minuk GY, Lui RC, Kelly JK. Rupture of the liver associated with acute fatty liver of pregnancy. Am J Gastroenterol 1987; 82: 457-460

[26] Sang C, Wang S, Zhang Z et al. Characteristics and outcome of severe preeclampsia/eclampsia concurrent with or complicated by acute pancreatitis: a report of five cases and literature review. J Matern Fetal Neonatal Med 2019; 32: 633-640

[27] Rath W. Das HELLP-Syndrom: eine interdisziplinäre Herausforderung. Dtsch Ärztebl 1998; 95: 2997-3002

[28] Garcia-Romero CS, Guzman C, Cervantes A et al. Liver disease in pregnancy: medical aspects and their implications for mother and child. Ann Hepatol 2019; 18: 553-562

[29] Westbrook RH, Dusheiko G, Williamson C. Pregnancy and liver disease. J Hepatol 2016; 64: 933-945

[30] Minakami H, Takahashi T, Tamada T. Should routine liver biopsy be done for the definite diagnosis of acute fatty liver of pregnancy? Am J Obstet Gynecol 1991; 164: 1690-1691

[31] Minakami H, Oka N, Sato T et al. Preeclampsia: a microvesicular fat disease of the liver? Am J Obstet Gynecol 1998; 159: 1043-1047

[32] Rolfes DB, Ishak KG. Acute fatty liver of pregnancy: a clinicopathologic study of 35 cases. Hepatology 1985; 5: 1149-1158

[33] Dani R, Mendes GS, Medeiros J et al. Study of the liver changes occurring in preeclampsia and their possible pathogenetic connection with acute fatty liver of pregnancy. Am J Gastroenterol 1996; 91: 292-294

[34] Visser W, Wallenburg HC. Temporising management of severe preeclampsia with and without the HELLP syndrome. BJOG 1995; 102: 111117

[35] Mikolasevic I, Filipec-Kanizaj T, Jakopcic I et al. Liver disease during pregnancy: a challenging clinical issue. Med Sci Monit 2018; 24: 4080-4090

[36] Thomas T, Jophy R, Mhaskar A et al. Are we increasing serious maternal morbidity by postponing termination of pregnancy in severe pre-eclampsia/eclampsia? J Obstet Gynaecol 2005; 25: 347-351

[37] Meng J, Wang S, Gu Y et al. Prenatal predictors in postpartum recovery for acute fatty liver of pregnancy: experiences at a tertiary referral center. Arch Gynecol Obstet 2016; 293: 1185-1191

[38] Martin JN, Blake PG, Perry KG et al. The natural history of HELLP syndrome: patterns of disease progression and regression. Am J Obstet Gynecol 1991; 164: 1500-1509

[39] Tran TT, Ahn J, Reau NS. ACG Clinical Guideline: Liver Disease and Pregnancy. Am J Gastroenterol 2016; 111: 176-194
[40] Erkurt M, Berber I, Berktas HB et al. A life-saving therapy in Class 1 HELLP syndrome: Therapeutic plasma exchange. Transfus Apher Sci 2015; 52 : 194-198

[41] Levin G, Kalish Y, Attari R et al. Plasmapheresis-A lifesaving treatment for life threatening HELLP syndrome. Eur J Obstet Gynecol Reprod Biol 2019; 235: 125-126

[42] Rebahi H, Still ME, El Adib AR. A successful use of therapeutic plasma exchange in a fulminant form of acute fatty liver of pregnancy. J Gynaecol Obstet Hum Reprod 2019; 48: 133-137

[43] Wang HY, Jiang Q, Shi $\mathrm{H}$ et al. Effect of caesarean section on maternal and foetal outcomes in acute fatty liver of pregnancy: a systematic review and meta-analysis. Sci Rep 2016; 6: 28826

[44] Reck T, Bussenius-Kammerer M, Ott R et al. Surgical treatment of HELLP syndrome - associated liver rupture - an update. Eur J Obstet Gynecol Reprod Biol 2001; 99: 57-65

[45] Hay JE. Liver disease in pregnancy. Hepatology 2008; 47: 1067-1076

[46] Wallace K, Harris S, Addison A et al. HELLP syndrome: Pathophysiology and current therapies. Curr Pharm Biotechnol 2018; 19: 816-826

[47] van Oostwaard MF, Langenveld J, Schuit E et al. Recurrence of hypertensive disorders of pregnancy: an individual patient data metaanalysis. Am J Obstet Gynecol 2015; 212: 624.e1-624.e17

[48] Leeners B, Neumaier-Wagner P, Kuse S et al. Recurrence risks of hypertensive diseases in pregnancy after HELLP syndrome. J Perinat Med 2011; 39: 673-678

[49] Ahmed KT, Almashhrawi AA, Rahman RN et al. Liver diseases in pregnancy: diseases unique to pregnancy. World J Gastroenterol 2013; 19: 7639-7646

[50] Xiong HF, Liu JY, Guo JM et al. Acute fatty liver of pregnancy: over six months follow-up study of twenty-five patients. World J Gastroenterol 2015; 21: 1927-1931

[51] Amaral LM, Cunningham MW, Cornelius DC et al. Preeclampsia: longterm consequences for vascular health. Vasc Health Risk Manag 2015; 11: $403-415$

[52] Chen CW, Jaffe IZ, Karumanchi SA. Preeclampsia and cardiovascular disease. Cardiovasc Res 2014; 101: 579-586

[53] Davidson KM, Simpson LL, Knox TA et al. Acute fatty liver of pregnancy in triplet gestation. Obstet Gynecol 1998; 91: 806-808

[54] Shekhawat P, Bennett M], Sadovsky Y et al. Human placenta metabolizes fatty acids: implications for fetal fatty acid oxidation disorders and maternal liver diseases. Am J Physiol Endocrinol Metab 2003; 284: E1098E1105

[55] Haram K, Mortensen JH, Mastrolia SA et al. Disseminated intravascular coagulation in the HELLP syndrome: how much do we really know? J Matern Fetal Neonatal Med 2017; 30: 779-788

[56] Rajasri AG, Srestha R, Mitchell ]. Acute fatty liver of pregnancy (AFLP) an overview. J Obstet Gynaecol 2007; 27: 237-240 